\title{
Essencialismo e crítica social n' O Crime de Lorde Arthur Savile de Oscar Wilde
}

\author{
Essentialism and social criticism in 'The Crime of Lord Arthur Savile by Oscar \\ Wilde
}

\author{
NICOLE ELOUISE AVANCINI ${ }^{1}$
}

\begin{abstract}
Resumo: O presente artigo tem como objetivo analisar o conto $O$ crime de lorde Arthur Savile, do escritor, poeta e dramaturgo irlandês Oscar Wilde, que narra as decisões tomadas pelo protagonista após ser indicado, por um quiromante, que seria o autor de um assassinato. Para tal, partimos do artigo Performative and Subversive: Oscar Wilde's 'Lord Arthur Savile's Crime' de Masahide Kaneda, que interpreta o conto a partir de conceitos da linguística e da semiótica de Ferdinand de Saussure. Nesse texto, é defendido que a estória representa um antiessencialismo, por ilustrar como a realidade é construída do mesmo modo em que se dá a estruturação da linguagem, isto é, de modo performativo, além de estar sujeita a interpretações arbitrárias. Neste trabalho, entretanto, pretendemos contraargumentar tal posicionamento. Em nossa teorização, realizamos uma análise do contexto em que a obra foi escrita - a Inglaterra vitoriana do final do século XIX - e adotamos como base excertos do ensaio de Wilde $A$ alma do homem sob o Socialismo, bem como algumas ideias apresentadas por Liam Lynch em seu artigo Complex Truth from Simple Beauty: Oscar Wilde's Philosophy of Art. Com isso, enfatizamos, primordialmente, o aspecto de crítico social do escritor, propondo que ele acreditava, de fato, numa essência intrínseca humana a ser desenvolvida por meio da liberdade de ação. Por conseguinte, identificamos o conto como uma representação dessa sua visão, que tem como finalidade promover uma objeção aos valores impostos pela sociedade da época - exercendo, assim, seu papel de sátira.
\end{abstract}

Palavras-chave: Oscar Wilde. Conto. Essencialismo. Crítica social.

Abstract: This article aims to analyze The tale of Lord Arthur Savile, by Irish writer and poet and playwright Oscar Wilde, which chronicles the decisions taken by the protagonist after being indicated by a palmist who would be the author of a murder. For that, we start from the article Performative and Subversive: Oscar Wilde's 'Lord Arthur Savile's Crime' by Masahide Kaneda, who interprets the tale from the concepts of linguistics and the semiotics of Ferdinand de Saussure. In this text, it is argued that the story represents an antiessentialism, to illustrate how reality is constructed in the same way in which the structuring of language occurs, that is, in a performative way, besides being subject to arbitrary interpretations. In this work, however, we intend to counter-argument such positioning. In our theorising, we conducted an analysis of the context in which the work was written - Victorian England at the end of the nineteenth century. Its based on excerpts from Wilde's essay The Soul of Man under Socialism. As well as some ideas presented by Liam Lynch in article Complex Truth from Simple Beauty: Oscar Wilde's Philosophy of Art. In this, we primarily emphasize the writer's social critic, proposing that he believed, in fact, in an intrinsic human essence to be developed through freedom of speech action. We therefore identify the tale as a representation of this view, which aims to promote an objection to the values imposed by society at the time - thus exercising its role of satire.

Keywords: Oscar Wilde. Tale. Essentialism. Social critic.

1 Graduanda em Filosofia pela Universidade Estadual do Oeste do Paraná. E-mail:
nicole_avancini@hotmail.com. 


\section{Introdução}

Em 1891, sob o título original de Lord Arthur Savile's Crime and Other Stories, o escritor irlandês Oscar Wilde apresenta-nos uma coletânea de quatro contos sendo o quinto adicionado em edições posteriores. Um deles, o qual dá nome ao livro, é o tema que o presente artigo propõe estudar.

A curta estória retrata as atitudes tomadas pelo protagonista, Lord Arthur Savile, após ter seu destino revelado por meio da quiromancia, realizada pelo sr. Septimus Podgers. Examinada sua mão, Arthur é previsto como autor de um assassinato, e logo reconhece isso como um dever - o dever de realmente cometer o ato para que, só então, tenha o direito de casar-se com Sybil Merton.

Masahide Kaneda, em seu artigo Performative and Subversive: Oscar Wilde's "Lord Arthur Savile's Crime", analisa tal conto relacionando a caracterização das personagens à maneira como a linguística é desenvolvida. De acordo com ele, a realidade do protagonista é concebida de modo performativo, análogo ao modo geral de construção da linguagem literária. Ou seja, valendo-se de termos da semiótica de Saussure, o autor defende sua tese de que o conto trata de uma representação alegórica da performatividade da linguagem, identificada nos efeitos da quiromancia. Sendo assim, Kaneda argumenta em torno de um antiessencialismo em Wilde, baseado na constatação de que as ações cometidas por Arthur advêm de sua própria interpretação dos sinais que lhe são apresentados, à medida que decorre a estória. Assim, é inferido que não há uma natureza inerente à referida personagem, pois seu caráter é construído conforme sua leitura particular dos sinais.

Além disso, Kaneda afirma que o senso da personagem é invertido quando decide por cometer o homicídio, demonstrando como os significados são arbitrários. $\mathrm{O}$ autor afirma não haver explicação exata ao que controla suas ações, mas sugere que a quiromancia é a metáfora para o caráter performativo, e os atos de Arthur seriam produtos de sua interpretação arbitrária dos acontecidos da narrativa.

No entanto, teria lorde Arthur Savile cometido o crime se não soubesse, de fato, de seu destino? Propomos, então, no presente trabalho, uma análise sob outra perspectiva. Defendemos que o personagem fora, de fato, corrompido por tal revelação e impelido a agir de forma contrária a sua real natureza e vontade. Logo, o conto trata de uma crítica às virtudes valorizadas na sociedade vitoriana, a qual parece-nos concretizar o conceito de determinismo com a presença de uma autoridade que retira liberdades individuais e conduz a um conformismo.

Primeiramente, partimos da constatação de que Oscar Wilde era um crítico social - não somente em seus ensaios, mas, sobretudo, em suas obras de ficção - e que tal fato viu-se refletido na construção de seus escritos. Por isso, tomaremos

\footnotetext{
${ }^{2}$ KANEDA, 1999, p. 81-98.
} 
como base excertos de $A$ alma do homem sob o Socialismo 3 (também publicada em 1891), na qual o escritor critica as demandas da sociedade Vitoriana do século XIX como responsáveis por suprimir as verdadeiras intenções humanas e impedirem-nos de desenvolver uma personalidade intrínseca. Assim, caminharemos à proposição de que Wilde era, com efeito, um essencialista.

A tal argumento, aliaremos a seção Aristotle and That at Which Everything Aims do artigo Complex Truth from Simple Beauty: Oscar Wilde's Philosophy of Art, de Liam Lynch ${ }^{4}$, o qual explana como o escritor irlandês inspirou-se em Aristóteles para reprovar as virtudes enaltecidas socialmente na época - entre elas, o dever, que é retratado no conto em questão. Nesse artigo, Lynch defende que também influenciaram Wilde as noções do grego de que a vida humana pressupõe uma evolução - conceituação que podemos averiguar no ensaio previamente citado e que nos parece estar implícita no conto.

Portanto, em concordância com Kaneda, defendemos que a narrativa trabalhada é uma alegoria - mas a diferença está no fato de que indicamos uma implícita crítica. Por isso, concluímos que Arthur é a vítima das imposições do social, representadas por uma autoridade (no caso, sr. Podgers e a quiromancia), que corrompe sua natureza e que dita suas ações, sendo que a personagem só pode ver-se livre ao combater essa realidade - o que, de fato, ocorre no desfecho da estória, após algumas tentativas.

\section{1. $O$ contexto}

A Era Vitoriana ${ }^{5}$ foi o período em que a Inglaterra esteve sob o governo da rainha Vitória I, compreendido entre 1837 e 1901. Essas décadas foram marcadas pelo desenvolvimento político-econômico inglês e um significativo aumento demográfico, principalmente devido à Segunda Revolução Industrial e à promoção do neocolonialismo, que consolidaram o país como uma potência mundial. Intelectualmente, vivenciou-se grandes avanços nas áreas da medicina, biologia, física, psicologia e sociologia. Já a literatura da época, compreendida entre os períodos do Romantismo e do Realismo, consolidou diversos autores, tanto na prosa quanto na poesia, e explorou temas sociais com lições morais.

Apesar de todo esse progresso, a sociedade vitoriana contava com muita desigualdade. A classe alta concentrava uma poderosa aristocracia, o que contrastava com a classe trabalhadora, a qual enfrentou as consequências das largas demandas industriais - péssimas condições de vida, altas cargas horárias, trabalho infantil, prostituição e pobreza. Além disso, uma característica marcante dessa sociedade foi o conservadorismo, que culminou em perseguições a escritores e

\footnotetext{
${ }^{3}$ WILDE, 2004.

${ }^{4}$ LYNCH, 2014.

${ }^{5}$ Disponível em: http://www.victorian-era.org/victorian-era-society.html (acesso em: 11/o8/2018)
} 
artistas que discordavam do sistema vigente, como Oscar Wilde. Esse fato, no entanto, não o impediu de escrever suas críticas, seja na forma de ensaios, seja implícito em seus romances e curtas estórias.

\section{Uma breve descrição do enredo}

O crime de Lord Arthur Savile foi publicado, individualmente e pela primeira vez, em 1887, na revista literária britânica The Court and Society Review, conhecida por publicar os trabalhos de Wilde. Dado o contexto em que foi escrita, e o teor da maioria dos escritos de Wilde, a narrativa retrata aspectos da sociedade da época. $\mathrm{O}$ início é ambientado numa festa, onde encontram-se os mais diversos membros da aristocracia: ministros, duques, princesas e integrantes da Royal Academy; a anfitriã é lady Windermere, que se mostra fiel credora na quiromancia no início da trama, e a responsável por apresentar sr. Podgers, o quiromante, aos convidados - entre eles, lorde Arthur Savile, o protagonista. Este, observando o trabalho do quiromante com outros presentes, solicita que sua mão seja, também, examinada - tarefa que, quando executada, leva tempo para ser concluída, pois Podgers logo pressente algo de diferente, mas não o revela. Arthur, preocupado com sua esposa e seu casamento, teme por ter seu destino revelado e possivelmente interrompido, mas, mesmo assim, oferece dinheiro pela resposta. O quiromante, então, expõe que o lorde seria o autor de um homicídio - a partir disso, a trama se desenrola em torno da decisão de Arthur por cometer, de fato, o crime.

\section{Uma análise - performativo e subversivo}

Apresentaremos, nesta seção, alguns pontos do artigo Performative and Subversive: Oscar Wilde's "Lord Arthur Savile's Crime”, de Masahide Kaneda, que serão discutidos na sequência. Contudo, em primeira instância, julgamos importante esclarecer alguns conceitos presentes no texto e que são utilizados para embasar sua argumentação.

No século XIX, Ferdinand de Saussure ${ }^{6}$, ao desenvolver sua teoria linguística, estabeleceu o conceito de signo como o núcleo de representação da linguagem, e como sendo o resultado da união entre o significante o significado. O significante indica a palavra, o conceito abstrato e imaterial que dá nome a um elemento real, concreto - e esse elemento é o significado. Os dois termos são, então, indissociáveis, porém essa relação é estabelecida de acordo com o princípio da arbitrariedade. Sendo assim, o sentido é criado conforme a interpretação que lhe é atribuída, seja por uma convenção ou por um entendimento pessoal.

Portanto, de fato, o autor nos apresenta uma análise muito interessante de tal conto, partindo do argumento de que a caracterização das personagens é feita da

\footnotetext{
${ }^{6}$ Disponível em: https://www.youtube.com/watch?v=mXMAU $5 \mathrm{Of}_{4} \mathrm{SI}$ (acesso em: 16/o8/2018)
} 
mesma maneira que a linguagem é formada - ou seja, ambas possuindo um caráter performativo. Com isso, ele propõe que as personalidades na obra são produzidas de modo arbitrário, dependendo da interpretação que atribuem a sua própria realidade. Diz o autor sobre a cena inicial do conto: “(...) o caráter é algo instável e, além disso, é criado por meio da interpretação: essa introdução sugere crucialmente que é pela interpretação dos signos, quer verbal ou não, que os significados são identificados numa maneira arbitrária.” (KANEDA, 1999, p. 84)7. Essa forma de caracterização é atribuída não apenas a Arthur, mas, também, aos outros presentes na festa, que, segundo o autor do artigo, apresentam desarmonias entre seus títulos sociais e suas ações.

A quiromancia, nesse artigo, é tratada como uma hermenêutica, que abre a possibilidade de interpretações para que sejam criados os significados. Assim, é argumentado que a significação também envolve convenções sociais, e é indicado o termo "iterabilidade", a desconstrução de um signo, abordado por Derrida:

[...] isso dá oportunidade para detectar o modo como os significados são criados nas práticas discursivas. Isso envolve o procedimento interpretativo oculto na significação. A leitura das mãos feita por Podgers simbolicamente indica que a interpretação está sempre em processo. Mesmo assim, Arthur cegamente acredita no que é dito sobre seu futuro e decide cumprir com seu dever (KANEDA, 1999, p. $87)$.

Com a decisão de Arthur por realmente cometer o crime, é afirmado: "Seu senso é exageradamente invertido, o que indica como os significantes e os significados tornam-se caóticos por meio de sua própria interpretação." (KANEDA, 1999, p. 85). Assim, ele reforça o caráter arbitrário que previamente atribuiu às ações da personagem, e conclui sua primeira defesa do argumento de que há a conceituação de um antiessencialismo no conto: "Se o caráter, como a ficção repetidamente alega, não está fixado na substância de cada personagem, mas é produzido por meio das jogadas dos sinais, isso engendra a noção antiessencial do eu" (KANEDA, 1999, p. 85).

O autor afirma não haver resposta ou, até mesmo, não haver necessidade de uma quanto à questão de quem seria o verdadeiro responsável por ludibriar Arthur a cometer o crime. No decorrer do artigo, entretanto, encontramos possíveis sugestões: o autor afirma que o poder da palavra "assassino", que ecoa na cabeça da personagem e tem uma força ilocucionária e perlocucionária (persuasivas), leva-o a realizar o crime. Além disso, o Destino, no conto, é descrito como uma força desconhecida e inevitável, na qual Arthur é levado a crer. Ademais, há, também, o fato de Arthur ter definido seu casamento como recompensa para a execução do assassinato, que é visto como um dever, o que desenvolveremos adiante. Portanto, é

\footnotetext{
${ }^{7}$ Todas as traduções são da autora.
} 
argumentado que o protagonista permanece alheio à tese da formação arbitrária da realidade, e apenas age como acredita que deve agir.

Kaneda, ainda, abre reflexões a respeito da veracidade da quiromancia de Podgers, isto é, se ele realmente foi capaz de ler a mão de Arthur, ou se apenas o fez para receber dinheiro em troca. A respeito disso, argumenta ser difícil determinar, e reforça sua tese principal: "[...] indeterminação no sentido de que nunca há a verdade, mas apenas uma verdade constituída pelos efeitos performativos (KANEDA, 1999, p. 93)". Porém, o que ele defende veementemente é que Arthur permanece abstraído com relação aos ditos efeitos performativos da quiromancia e quanto ao caráter arbitrário de formação da realidade a partir da interpretação. Com isso, propõe que o conto é uma alegoria ao modo como o mundo é constituído:

O crime de Lord Arthur Savile, em diversos sentidos, alegoricamente informa essa natureza crucial da formação do mundo, que se estende para além da construção da ficção até o mundo real. Narrado bem-humoradamente na superfície, essa ficção expõe o modo como ideologias criam nosso mundo por meio da imposição de ilusões da substância. A narrativa sustenta que não há nada além da interpretação de sinais no mundo (KANEDA, 1999, p. 93-94).

O autor finaliza seu artigo, portanto, defendendo o valor subversivo que a narrativa expõe. Sendo o mundo resultado de interpretações arbitrárias dos sinais, ele conclui que não há uma essência, ou seja, tudo é mera construção. Por isso, ao defender o conto como representante de uma força subversiva, ele atenta ao modo fortuito como uma ideologia é formada e como o caráter não é algo fixo.

\section{A natureza humana em Wilde}

Nesta seção, exploraremos brevemente outro texto do escritor irlandês, de modo a expor sua visão acerca de alguns pontos que serão base para a comprovação dos argumentos defendidos neste artigo.

Na obra A alma do homem sob o Socialismo, escrita em 1891, Wilde expõe suas críticas aos valores ressaltados pela sociedade capitalista, defendendo o Socialismo não-autoritário como possível solução a essas mazelas e um caminho para o Individualismo - com esse conceito, ele promove a liberdade que cada indivíduo deveria ter de seleção e aprimoramento de seus próprios ofícios, sem qualquer tipo de coação. Para tal, ele defende a extinção da propriedade privada e da competição, argumentando que a mecanização substituiria o trabalho braçal humano. Assim, livres dessa carga, sobraria tempo para dedicar-se à criação artística. Em suas palavras:

A admissão da propriedade privada, de fato, prejudicou o Individualismo e o obscureceu ao confundir um homem com o que ele possui. Desvirtuou por inteiro o 
Individualismo. Fez do lucro, e não do aperfeiçoamento, o seu objetivo. De modo que o homem passou a achar que o importante era ter, e não viu que o importante era ser. A verdadeira perfeição do homem reside não no que o homem tem, mas no que o homem é (WILDE, 2004, p. 7).

Com isso, identificamos que Wilde concebe cada homem como um ser que possui uma individualidade, e relaciona essa tese a sua crítica. Apesar de caracterizar tal natureza individual com o uso de adjetivos positivos, também afirma a naturalidade da ambição e da desobediência - sobre este conceito, o escritor irlandês defende constituir o meio para o progresso, além de alegar que, onde há autoridade, há seu combate. Essa individualidade, no entanto, estaria oprimida pelas exigências da rotina numa sociedade industrial, que mantém o foco na aquisição de bens e riquezas. Assim, podemos constatar como Wilde reprova os valores sociais da época:

Numa sociedade como a nossa, em que a propriedade confere distinção, posição social, honra, respeito, títulos e outras coisas agradáveis da mesma ordem, o homem, por natureza ambicioso, fez do acúmulo dessa propriedade seu objetivo, e perseguirá sempre esse acúmulo, exaustivo e tedioso, ainda que venha a obter bem mais do que precise, possa usar ou desfrutar, ou mesmo que chegue até a ignorar quanto possui (WILDE, 2004, p. 7).

Se, mesmo nessas circunstâncias, o homem for capaz de encontrar meios para que seja possível seu desenvolvimento intelectual, o autor encontra nisso uma explicação para a subjugação ao sistema. Porém, ele lamenta a situação daqueles que, sem buscar sua prosperidade interior, entregam-se totalmente à vida laboriosa, e tenta justificá-la ao alegar que: “(...) as desgraças da pobreza são degradantes ao extremo e exercem de tal forma um efeito paralisador sobre a natureza humana que classe alguma tem consciência de seu próprio sofrimento.” (WILDE, 2004, p. 5). Com o intuito de livrar-se dessa subjugação, o escritor ressalta que é por meio da contemplação da arte que se possibilita a formação de um senso crítico (criticismo contemplativo), capaz de promover revoluções individuais e sociais. Pois, visto que essa postura conduziria a uma transformação na personalidade de um homem, que deixaria de ser egoísta e tornar-se-ia altruísta e benevolente, consequentemente, promover-se-iam transformações sociais.

Diante disso, extraímos a conclusão de que Oscar Wilde acreditava que a pobreza, a insegurança da classe operária, os trabalhos muito exigentes e a opressão produzidas em uma sociedade capitalista prejudicavam o desenvolvimento da natureza humana, uma suposta essência intrínseca. Assim, ele defende que, sob um sistema socialista não-autoritário, tais exigências desvanecer-se-iam e o homem verse-ia livre para exercer suas próprias vontades. Dessa maneira, abrir-se-ia caminho para se alcançar uma espécie de Individualismo "não-capitalista”, isto é, aquele 
voltado ao puro altruísmo, sem competitividade, que apenas visa ao desenvolvimento interior de cada um.

\section{Uma outra perspectiva}

Apesar de a proposta de Masahide Kaneda a respeito do conto em questão ser muito bem colocada e desenvolvida, para ser considerada efetivamente válida, seria necessário, antes, ponderar se Wilde tomara conhecimento das obras de Saussure. Por isso, nesta seção, propomos uma análise tomando por base as ideias próprias do autor irlandês.

Oscar Wilde produziu escritos em prosa e em verso, incluindo ensaios, diálogos, peças e cartas. Ele era adepto aos movimentos dândi e esteticista, além de possuir uma visão libertária sobre o mundo, conforme o exposto. No final de sua vida, foi sentenciado a dois anos de prisão por comportamento indecente e sodomia - o que não o impediu, entretanto, de continuar produzindo.

O crime de lorde Arthur Savile, assim como outras de suas obras (O retrato de Dorian Gray e A importância de ser prudente, para citar algumas), é um texto que, se analisado tendo em vista o lado "filósofo" do autor e suas fortes opiniões, permite profundas interpretações. O nosso objetivo é demonstrá-lo como uma ilustração daquilo que Oscar tanto criticava.

Logo na abertura do conto podemos inferir essa suposta intenção, visto que somos situados quanto à ambientação e ao perfil das personagens principais e secundárias. Portanto, a crítica parte não de um ponto de vista fora dessa realidade, mas, de fato, o autor parte da própria esfera da classe alta para criticá-la. Lady Windermere, a anfitriã da festa, é quem logo faz "propaganda" do quiromante, apresentando-o e despertando a atenção de alguns convidados, revelando-se uma fiel credora dessa prática: "[...] se o meu polegar tivesse sido um pouquinho mais curto, eu seria uma pessimista convicta." (WILDE, 1994, p. 85). Um aspecto a que conferimos atenção é que a descrição de sr. Podgers, apresentada do ponto de vista de lady Windermere, quem o conhece bem, deixa evidente a dicotomia entre aparência e realidade - oposição que se torna efetiva na proposta de opressão e corruptibilidade que se desenvolve ao longo da estória, para mascarar como inofensivo esse personagem:

Bem, ele não se parece nem um pouco com um quiromante. Quero dizer que não é misterioso, ou esotérico, nem de aparência romântica. É um homem pequeno e gordinho, com uma careca engraçada e óculos de aros dourados; algo assim entre um médico de família e um advogado do interior. Sinto muito, mas realmente não tenho culpa. As pessoas são tão contrariantes (WILDE, 1994, p. 85). 
Sr. Podgers, expondo o passado, o futuro e características do caráter dos convidados, desperta a curiosidade de lorde Arthur Savile. Tímido, pede para que lady Windermere os apresente, a qual logo diz que contará todo o resultado à Sybil, companheira de Arthur - a respeito disso, ele não parece se preocupar, de início. No entanto, no primeiro contato de Podgers com a mão de Arthur, quebra-se o clima descontraído que se firmara em meio às outras revelações, mudando-se até a conduta do quiromante:

Porém, quando o sr. Podgers olhou a mão de lorde Arthur, ficou curiosamente pálido e não disse nada. Um arrepio pareceu atravessá-lo, e suas imensas e fartas sobrancelhas tremeram convulsivamente, do modo estranho e irritante que costumavam fazer quando ele se via perplexo (WILDE, 1994, p. 90).

Disfarçando, porém sem passar despercebido por Arthur, Podgers revela-lhe alguns acontecimentos comuns e logo encerra. Apenas após ter sido oferecido alguns guinéus é que ele resolve por revelar o que havia visto de peculiar - sobre isso, podemos levantar o questionamento quanto à veracidade da fala de Podgers: se ele era, de fato um quiromante, ou apenas iludia as pessoas, chocava-as, contava-as o que sabia que queriam ouvir, somente para manter a clientela e continuar recebendo seu dinheiro. Para o desenvolvimento de nossa tese, no entanto, a resposta a tal questão mantém-se indiferente, uma vez que o papel representado por esse personagem efetiva-se independentemente da honestidade de seu diagnóstico.

Confrontando-se com a dúvida, Arthur sente medo, pavor, "um mal iminente", o que demonstra o poder da palavra de Podgers sobre ele, mesmo antes de tomar conhecimento dela - e é a fala dele que desperta Arthur a questionar os rumos de sua vida a partir desse momento:

Sempre levara a vida delicada e luxuosa de um jovem de berço e fortuna, uma vida requintada em sua independência de quaisquer preocupações sórdidas, em sua irresponsabilidade juvenil; agora, pela primeira vez, tomara consciência do terrível mistério do Destino, do horrível significado da Fatalidade (WILDE, 1994, p. 9192).

Esse excerto deixa-nos claro o caráter determinista que se desenvolve na trama. Ou seja, Arthur é levado a acreditar que seu futuro já está, de fato, traçado e ele deve apenas conformar-se e agir segundo deve. Não trata, portanto, de mera interpretação atribuída à quiromancia, pois ele poderia escolher ignorar Podgers não o fez devido à credibilidade que lhe fora concedida por lady Windermere e os demais convidados. Identificamos, portanto, na quiromancia, uma força, evidentemente subversiva, que impele o protagonista a perseguir o que lhe fora imposto, mesmo apesar de ele ser resistente a tal ideia, a princípio: 
Não passamos nós de peças de xadrez movidas por algum poder invisível, vasos moldados à vontade pelo fabricante de potes, para a honra ou para a vergonha? Sua razão voltava-se contra tal ideia. Sentia, porém que uma tragédia pesava sobre ele, e que seria repentinamente chamado a arcar com uma carga insuportável (WILDE, 1994, p. 92).

Essa força e essa subversão seriam a representação de como alguns valores socialmente difundidos - o dever e o forte moralismo, por exemplo - interferem na vida e na tomada de decisões de um cidadão. Apesar de Arthur não pertencer à classe operária, portanto não sofrendo com as mazelas da vida laboriosa, ele sofre com o peso do dever que é imposto sobre ele, ou melhor, que ele próprio impõe sobre si. Mesmo pertencendo à classe alta, ele não se encontra imune às pressões de adequar-se às normas.

Somado a isso, há a questão do casamento com Sybil, que também motiva Arthur a tomar uma atitude: "Compreendeu que casar-se com ela, com a fatalidade do assassinato pairando sobre sua cabeça, seria traição semelhante à de Judas [...]. Que felicidade poderia existir para eles, quando a qualquer momento ele poderia ser chamado a cumprir a aterradora profecia escrita em sua mão?" (WILDE, 1994, p. 98).

O casamento na era Vitoriana, especialmente entre membros da classe alta, era muito valorizado. Para as jovens mulheres, era um evento importantíssimo, pois seus papéis principais na sociedade eram o de mãe e o de esposa. Por parte dos homens, restava concedê-las o máximo respeito, e cada detalhe do casamento, desde o baile de apresentação da moça à sociedade até a lua de mel, era meticulosamente cuidado. Por isso, Arthur assume que seria uma desonra a sua noiva se ele desconsiderasse seu destino, ou se adiasse a celebração, pois "Havia mais do que mera paixão em seu amor; e Sybil era para ele um símbolo de tudo que existe de bom e de nobre. [...] Seu coração disse-lhe que não se tratava de pecado, mas de um sacrifício; sua razão lembrou-lhe que não existia outro caminho." (WILDE, 1994, p. 98). Na obra A alma do homem sob o Socialismo, encontramos críticas a esses dois conceitos, afirmando que o dever "significa tão-só-fazer o que os outros querem porque assim querem", que o auto-sacrifício “é tão-só uma sobrevivência da mutilação selvagem.” (WILDE, 1994, p. 27).

Nesse ponto da estória, há uma inversão no comportamento de Arthur. Apenas um dia se passa até sua tomada de decisão, e ele, que antes sentia medo e insegurança perante seu destino, acaba por declarar, veementemente, que cumpriria a tarefa: "Perguntava-se como poderia ter sido tão tolo que chegasse a gritar e lutar contra o inevitável.” (WILDE, 1994, p. 99). Essa é a subversão que pesa sobre o personagem: Podgers e a quiromancia representam a pressão social por enquadrarse nas regras morais disseminadas, que obliteram a liberdade e delimitam a vida e as escolhas pessoais; a decisão de Arthur representa o conformismo a que os cidadãos 
se sujeitam, ao ponto de acreditar que aquilo que lhe fora imposto é o melhor para si. Tendo essas ideias finalmente fixadas em sua mente, resta a Arthur determinar quem será sua vítima.

Primeiramente, após deliberar entre amigos e familiares, escolhe lady Clementina Beauchamp, uma senhora e sua prima de segundo grau, bem como o envenenamento como o melhor método. Ele compra uma cápsula, guarda-a numa bonbonnière e leva-a pessoalmente até a casa da senhora. Devido ao fato de ela sofrer de uma aflição cardíaca, Arthur a convence de que a cápsula é, na verdade, um remédio, que deve ser ingerido ao sentir as dores que antecedem um ataque, a fim de apaziguá-lo. Desse modo, seria possível simular uma morte natural. Arthur, então, sai de viagem à Veneza, com a consciência plena de haver cumprido seu dever. Lá, ele recebe a notícia de que lady Clementina havia falecido, porém não de acordo com seu plano. Ao retornar, descobre que a cápsula não fora ingerida e o motivo da morte fora, de fato, sua frágil condição.

Frustrado, Arthur leva algum tempo para se recompor, mas ainda mantém sua decisão. Na segunda tentativa, escolhe seu tio como vítima, o deão de Chichester. Sendo ele um apaixonado colecionador de relógios, o protagonista toma proveito e encomenda uma peça com um mecanismo explosivo para oferecê-lo como presente. Feita a entrega e passados alguns dias, não encontra menção nos jornais sobre a possível morte do deão. Mas, após mais algum tempo, Arthur lê uma carta que sua mãe havia recebido da decania de Chichester, que relatava sobre o presente recebido - de fato, ele funcionava como um despertador, e dava apenas pequenas explosões ao longo do dia. Ou seja, nada que pudesse ser uma ameaça a alguém.

Vendo seu plano falhar mais uma vez, Arthur se entristece. Sobre isso, o narrador afirma: "Tentara cumprir seu dever, porém o próprio Destino o traía. Sentia-se oprimido com a sensação da esterilidade das boas intenções, da futilidade de tentar ser correto." (WILDE, 1994, p. 114). Ressaltamos, por conseguinte, que o personagem está disposto a cometer o crime somente porque ele acredita que é o que lhe está determinado, a ponto de compreender sua decisão como uma boa intenção e, qualquer ação que destoasse disso, seria incorreta. Portanto, concluímos que, se Arthur não soubesse de seu destino, ele não viria a cometer o assassinato.

O que se desenrola na trama a seguir é, no mínimo, surpreendente. Enquanto caminhava por Londres após um jantar no clube, Arthur avista um homem escorado num parapeito às margens do rio Tâmisa. Quando o sujeito vira o rosto em direção ao protagonista, a luz do lampião revela que é sr. Podgers. Sem pensar duas vezes e num piscar de olhos, Arthur agarra-se a ele e atira-o no rio. Pouco tempo depois, os jornais noticiam o ocorrido como um caso de suicídio e, imediatamente, Arthur vai de encontro à Sybil para propor que eles se casem no dia seguinte. 
Em vista disso, interpretamos que o assassinato do quiromante - o qual seria a representação da autoridade opressora - assume um valor simbólico: o combate às pressões que tanto afligem o protagonista. Após falhar nas suas tentativas de concluir seu dever, Arthur resolve a questão de uma maneira que lhe permite, finalmente, ver-se livre. O que Wilde havia escrito n'A alma homem sob o socialismo a respeito do alcance de uma individualidade vê-se representado aqui: desvencilhado das imposições, Arthur pode, finalmente, realizar suas reais vontades novamente, isto é, casar-se. Mesmo sendo responsável pela morte de um homem, isso não deve, necessariamente, defini-lo como um criminoso, visto que o autor é da opinião de que as ações de um indivíduo podem ser admissíveis se há uma motivação maior por trás, conforme escreve em seu ensaio:

A personalidade é coisa muito misteriosa. Não se pode medir um homem pelo que ele faz. Um homem pode seguir a lei, e no entanto ser desprezível. Pode violar a lei, e no entanto ser justo. Pode ser mau, sem nunca ter feito nada de mau. Pode cometer um pecado contra a sociedade, e no entanto alcançar por meio desse pecado a verdadeira perfeição (WILDE, 2004, p. 10).

De fato, o autor parece acreditar numa suposta perfeição a ser atingida pelos homens. Liam Lynch, na seção intitulada Aristotle and That at Which Everything Aims, de seu artigo Complex Truth from Simple Beauty: Oscar Wilde's Philosophy of Art, apresenta Oscar Wilde como um leitor das obras dos gregos antigos, e afirma que ele fora influenciado pela ideia aristotélica de que o homem tende a alcançar uma vida elevada, ao contrário de simplesmente mantê-la tal como é:

A escrita de Wilde mostra sua frustração com a falta de consciência contemporânea da mediania de Aristóteles entre as virtudes, e com a ênfase vitoriana nas noções de dever, castidade e caridade como as virtudes mais elevadas. Na curta estória "O crime de lorde Arthur Savile" (1887), a ênfase extrema colocada, pelos vitorianos, no senso de dever é abrangida no assassinato de Podgers antes de Arthur casar-se com Sybil: homicídio depois do casamento causar-lhe-ia vergonha, e ele reconheceu "onde estava seu dever, e por tomou plena consciência de que não tinha direito de casar-se enquanto não houvesse cometido o assassinato". Ele também indica uma relação entre virtudes vitorianas como o dever e a falta de reflexão quando o narrador diz de lorde Savile: "A vida para ele significava ação, mais do que pensamento. Ele tinha o mais raro dos dotes, o bom senso" (LYNCH, 2014, p. 17).

Portanto, é justamente essa noção aristotélica que ele considera estar representada no conto de que tratamos, além das questões a respeito dos valores sociais da época, como abordamos.

Ao final do conto, alguns anos se passaram quando Arthur e Sybil, já com dois filhos, recebem a visita de lady Windermere. Ela traz à tona o assunto da 
quiromancia e confessa que sr. Podgers era um impostor. A respeito disso, podemos ponderar se, conforme já exposto, os diagnósticos feitos pelo quiromante não eram mesmo legítimos, ou se lady Windermere simplesmente não acreditava nessa prática, e toda a manifestação que ela havia feito em torno dela foi apenas para atrair e entreter seus convidados. Porém, quando questiona a Arthur se ele realmente acredita na quiromancia, e ele responde que a ela deve toda a felicidade de sua vida (neste caso, Sybil), o conto encerra com lady Windermere exclamando: "Que tolice! Nunca ouvi tamanha tolice em toda a minha vida" - essa fala evidencia o conto como uma sátira, que tem a finalidade de criticar, efetivamente, toda a estrutura social do período vitoriano.

\section{Referências}

LYNCH, L. "Aristotle and that at which everything aims". In: Complex Truth from Simple Beauty: Oscar Wilde's Philosophy of Art, Degree of Doctor of Philosophy of Curtin University, 2014.

KANEDA, M. Performative and subversive: Oscar Wilde's “Lord Arthur Savile's Crime”, Osaka Literary Review. 38, p. 81-98, 1999.

WILDE, O. Contos inéditos. Tradução: Barbara Heliodora. Rio de Janeiro: Nova Fronteira, 1994.

. A alma do homem sob o socialismo. Tradução: Mia Wallace e Vincent Veja, 2004. Acesso em:

https://libcom.org/files/WILDE,\%2oOscar.\%2oA\%2oalma\%2odo\%2ohomem\%2osob\%20o\% 2osocialismo.pdf

Submissão: 20.10.2018 / Aceite: 30.11.2018. 